\title{
Relationship between Pet Ownership, Pet Attachment and Decision to Have Children among Single People in the United States: A Need for Flexible Child Care Facilities in the United States
}

\author{
Diane Ezeh Aruah1', Virginia Obioma Ezeh², Cookey Ibiere Tom ${ }^{3}$ \\ ${ }^{1}$ College of communication and Journalism, University of Florida, Gainesville, Florida, USA \\ ${ }^{2}$ Use of English Unit, University of Nigeria, Nsukka, Nigeria \\ ${ }^{3}$ Mass Communication, University of Nigeria, Nsukka, Nigeria \\ Email: dezeharuah@ufl.edu
}

How to cite this paper: Aruah, D.E., Ezeh, V.O. and Tom, C.I. (2019) Relationship between Pet Ownership, Pet Attachment and Decision to Have Children among Single People in the United States: A Need for Flexible Child Care Facilities in the United States. Open Journal of Social Sciences, 7, 15-30.

https://doi.org/10.4236/jss.2019.79002

Received: June 26, 2019

Accepted: August 29, 2019

Published: September 2, 2019

Copyright $\odot 2019$ by author(s) and Scientific Research Publishing Inc. This work is licensed under the Creative Commons Attribution International License (CC BY 4.0).

http://creativecommons.org/licenses/by/4.0/

\begin{abstract}
Research has found that as pet ownership increases, fertility declines in the United States. Many single people have lost interest in growing families due to high cost of child care and lack of time. Other people speculate that it is easier to manage pets than children and pets give them more freedom than children. The main objective of this research therefore was to find out through Bowlby's attachment theory the extent to which preference to pet relates with other variables like pet attachment, security, loss, care and communication. The researcher developed six hypotheses and two research questions. Survey samples of 274 respondents were collected through Qualtrics using Amazon Mturk as recruitment platform. Ethical approval was gotten from an institute's review board. Studies show significant connection between pet attachment, pet security but show no significance to pet preference as many of the participants still prefer to have children. However, there is a need for government's intervention in terms of improving care for both pets and children.
\end{abstract}

\section{Keywords}

Pet Attachment, Pet Security, Pet Preference

\section{Introduction and Background}

In the United States today, there is a significant increase in the number of 
households who own pets. According to the 2017/2018 National Pet Owners Survey conducted by American Pet Products Association (APPA), sixty-eight percent of US households or about 85 million families own a pet, with dogs, cats, birds and horses ranking the highest number of pets owned by US households [1]. This is an incredible rise from what was recorded in 1988, of which pets owned by US residents were at the rate of 56 percent.

On why Americans are opting for pets instead of parenthood, [2] found that pets are cheaper to maintain than children, provide more freedom than children and do not require much attention like children. Also, Americans spend over $\$ 5$ billion annually feeding dogs and cats alone, while only $\$ 3$ billion is spent on baby food [3] [4]. Although many researchers have tried to investigate the usefulness of pets in overcoming depression, few studies have explained the kind of emotions people satisfy from owning a pet. [5] found that most studies on pet-human relationship focused on therapeutic, theoretical and physiological foundation and do not process, recognize or explain the roles pets play in the everyday lives of Americans.

[5] speculated that the neglect of pet in family studies could be as a result of social scientists' difficulty in identifying pets as members of the family. According to the authors, social scientist researchers on family studies focus solely on other family issues such as divorce, domestic violence and abortion, ignoring other pertinent family issues.

[6] argue that pets are good source of companions and have the tendency to make people feel secure and relieve themselves from stress. [7] added that pets serve as channels for expression of intense feelings and anguish that humans feel ashamed confiding in their fellow humans. [8] reiterates that attachment to pets offers emotional and social sustenance.

According to [9], 90\% of pet owners regard their pets as family members and a source of speedy recovery for older couples dealing with illnesses. [10] also indicated that pets like service dogs increase the social acceptability and acceptability of children and disabled people.

Psychologically, pets have been proven over the years to relieve distress, depression and insecurity [11]. Pets have also found to be of great impact to people who live alone. A study by [12] shows that pets serve as partners and companions to people who live alone. The study also revealed that pets are regarded as friends and a means of keeping fit. People who kept pets were considered to be more active, self-conscious, and communicative. Pets kept their owners active and occupied; they made them feel needed, and helped them to establish social contacts [13]. Again, recently, it can be observed in the United States that as pet ownership increases, fertility decreases. In surveys taken from the 1940s to the 1980s, fewer than half of Americans said they owned a pet. In 2006, America's 300 million humans own 360 million pets [14] and in 2011, the Pew Research Center reported that America's birth rate hit an all-time low in 2011-just 63 births per 1000 women of childbearing age. It was almost twice as high-123 
births per 1000 women - at the peak of the Baby Boom in 195 [15]. The implication of this data begs for the investigation of the relationship between pet ownership among single people and the desire to bear children. A Cleveland report in 2011 portrayed that households with married adults without children living at home spent the most on their pets, $\$ 698$ on average. However, there are few or no data or study carried out yet to ascertain if and why Americans have more pets than children, hence, the focus of this study.

In the past, Americans valued bearing children and were getting married in time. But recently, a CDC report showed that the fertility rate in the U.S. has hit a 30-year low, and Americans are not having enough babies to replace themselves [16]. Finances, cost of a child in the United States was found to be the major cause of having fewer numbers of children in the United States [16]. A New York Times's survey of why women's choice to have or not have children reveals that a quarter of the respondents who had children or planned to said they had fewer or expected to have fewer than they wanted because they fear they may not have time or money to take care of them [17]. Dog-loving ladies interviewed in the piece claim that dogs bring them as much joy as a baby would, with less work (no baby-sitters, no diaper changes, no need to save for college tuition).

Although the want for children has reduced, the need to love and have a companionship has not. Human beings still crave for someone to care for and nurture, and so they acquire pets. Pets can clearly provide the emotional attachment bond important in promoting a sense of security and well-being [18] [19] [20]. Some researchers predicted that attachment to pets is greatest in families where there is a limited number of significant others to function as sources of support and affection-families such as newlyweds, empty-nesters, and childless couples [21]. The number of single adults with pets increased over 16 percent from 2006 to 2011. As of 2012, 55 percent of single adults in the US were pet owners, as were 66 percent of families [22]. According to the American Veterinary Medical Association's 2012 US Pet Ownership \& Demographics Sourcebook, over the last five years, divorced, widowed and separated adults who own pets grew from 51 to 60 percent, Single men living alone who own pets increased from 34 to 44 percent and Single women living alone with a pet rose from 47 percent to 57 percent [22].

Pet bonding has been observed to be more beneficial than children; bonding with pets provides genuine and pure unconditional love and acceptance; [23] and pets stay with their owners as long as they are alive whereas children grow up and leave the home, sometimes forgetting to call or visit home [23] [24]. Pet attachment has been linked to pet loss [23] and the belief in an afterlife for a pet has been reported as a potentially helpful factor in coping with pet loss [25]. The emotions of pet owners could be tampered by the loss or death of a pet [26].

According to [27], grieving over the loss of a pet can have a devastating effect on the physical, cognitive, emotional, social and spiritual lives of pet owners. 
Even after death, majority of pet owners stay in touch with their pets, believing in the afterlife of their existence [28] [29].

Recently, it has been recognized that pets can be viewed as attachment figures whose loss elicits a significant grief response [30] that is similar to the response obtained by the death of a human attachment figure [18] [19] [20]. The death of a pet can be very stressful for families [31] and result in a sense of disruption in a family's usual way of functioning [32]. Given the many ways in which a pet can affect the functioning of a family system (e.g., communication, interaction, coping, etc.), it is normal to suppose that the death of a pet will have an earth-shattering blow on the daily routine and behavior patterns of a family. Pet owners who reside on their own and whose only friend was the lost pet could require professional support [33].

Specifically, elderly pet owners account less psychological distress and fewer doctor visits than those without pets, even when they do not live alone [11], and animal assisted therapy is so flourishing for all ages that it is now wide-spread in a variety of settings.

\section{Theoretical Foundations and Hypotheses}

Bowlby's attachment theory offers a framework for perceiving the magnitude of the connections that people establish with their pets [34]. According to Bowlby, the rationale for attachment is to sustain an affectional tie and give a sense of safety and security. These wants, which materialize very early in one's life and are typically directed toward a few specific people, tend to be enduring throughout one's life span. Bowlby's theory is based primarily on human-human attachment (particularly mother-infant bonding), but [35] has contended that any relationship can develop into an attachment relationship if it functions to accomplish needs for safety and security.

Pets can clearly provide the emotional attachment bond important in promoting a sense of security and well-being. In fact, an attachment to a pet may provide a person with something that is difficult to attain or sustain in relationships with people-a bond that is "pure" (i.e., a bond that is based on a genuine and consistent sense of unconditional love and acceptance).

It has been demonstrated in a recent study that animal companionship can provide a sense of nonjudgmental social support, a form of support that can be difficult for people (including supportive spouses or friends) to provide [36] [37] and for some, pets may become like surrogate friends, mates, or children [38]. The relationship with a pet can be especially significant in circumstances in which a person feels either physically or psychologically removed from human attachments or relationships. It is important to understand, though, that attachments to pets often occur in addition to consistent, healthy relationships with other people [39].

As attachment figures, pets can serve to lessen the effects of loneliness and social isolation, boost self-esteem, lessen anxiety and depression, act as a buffer against 
stressful life events, and facilitate social interactions with others [14] [34] [38] [40].

On a physical level, pet companionship has been found to serve as a stimulus for exercise, reduce the frequency of illness, speed up recovery from illness, lower blood pressure, and improve cardiovascular health [36] [38]. The bond that elderly people form with their companion animals may be stronger and more profound than for any other age group [41] [42].

Older people often develop stronger attachments to pets when they are deprived of other meaningful relationships [43].

Just looking at a dog, stroking or talking to it can trigger oxytocin, a hormone which elicits feelings of pleasure and eases stress. According to attachment theory, the loss of a loved figure can be the loss of an attachment relationship and could unleash a process of grief and mourning that feels almost unbearable.

The chemistry that ties people to their pets creates an emotional attachment that helps explain why pets mean so much to so many people, and attests to how they have come to be regarded as members of the family. Cain surveyed pet-owners in 11 states, she found that $87 \%$ of the respondents considered their pets to be members of the family, $36 \%$ said they thought of and treated their pets as people, and $37 \%$ indicated that pet ownership has helped them preserve and/or boost their social contacts and relationships [44].

\section{Pet Ownership and security}

Dogs have guarded our livestock, watched over our property, warned us of danger and protected our families often without the least bit of training. And they do it for nothing more than a pat on the head, a bite of kibble and a word of praise [45]. Cats pick up on things such as natural disasters, predators and disease that could hurt their humans and their world-all before we even see or hear them coming [46].

Their sense of smell and the fact they can be easily trained have led to dogs being used to help people in an extraordinarily diverse range of activities: therapy dogs are taken to nursing homes, hospitals, care centers for the disabled to engage with patients to help their quality of life by making them more sociable and encourage interaction and activities.

Rescue dogs have been trained to take on a number of tasks in searching for survivors after natural disasters such as earthquakes, tsunamis, fires, avalanches, etc. They assist firemen and policemen in tracking people and they rescue thousands of people across the world every year. Medical alert and detection dogs help in detecting cancer, but also have been trained to help people with severe forms of Diabetes, Narcolepsy, Addison's disease, and Epilepsy to ensure they get medical attention when necessary. These dogs save people's lives on a daily basis [47].

In light of the findings above, the following research questions and hypotheses were developed:

RQ1: What informs pet owners' decision to own a pet?

H1: The more single people acquire pets, the less likely they are to desire 
children

$\mathrm{H} 2$ : The more single people are attached to their pets, the less likely they are to want children

H3: People who experience high sense of security with their pets are less likely to desire children

H4: The longer people own their pets, the more they are attached their pets and not want children

H5: Older people who have pets are less likely to desire children

H6: People who have fear of losing their pets would take extreme care of them

\section{Methods}

\section{Sample}

The study was conducted using a survey instrument. Questionnaires were pretested to ensure validity and reliability. Single people who have pets were recruited through a popular online recruiting platform. A total of 300 participants were recruited, out of which 274 responses were $100 \%$ completed and recorded. Twenty six responses were either not completed or completed too quickly or too late.

The study was approved by an institutions' Institute Review Board as an exempt study with the number IRB201802918. Informed consent was obtained from the participants through Qualtrics survey platform. A screening question, "Do you have pets?" was set up to ascertain that only those who owned pet took the survey. The demographics of the sample are shown in Table 1:

Table 1. Demographics.

\begin{tabular}{ccc}
\hline Gender & No & $\%$ \\
Male & 118 & $43.1 \%$ \\
Female & 156 & $56.9 \%$ \\
Total & 274 & $100 \%$ \\
Race & & \\
White & 212 & $79.1 \%$ \\
African American & 17 & $13.8 \%$ \\
American Indian or Alaska Native & 0 & $0 \%$ \\
Native Haiwan or Pacific Islander & 12 & $0.4 \%$ \\
Hispanic & 7 & $2.6 \%$ \\
Multicultural & 19 & $7.1 \%$ \\
Others & 0 & $0 \%$ \\
Total & 274 & $100 \%$ \\
Age & Median 34.52 & Median 32.00 \\
\hline
\end{tabular}




\section{Measurement \\ Independent Variables \\ Pet Ownership/ background variables}

The first set of structured questions gathered information about parameters that could influence pet preference. The researcher measured pet ownership by asking five questions. The first question was opened ended, "How many pets do you have?" This was followed by two multiple choice questions, "What kind of pet do you have?" and "How did you get your pet?" The answer choices for pet kind include dog, cat, bird, multiples and others while the options for pet acquisition include bought it, found it, adopted it, and rescued it and others. Fourthly, the respondents were asked to rate on a scale of 0 to 10 , where 0 is not at all and 10 is very much, why they got their pets. Answer options for this question include medical purpose, comfort, companionship, security, to save life and adorn home. Lastly, the respondents were asked how long they have owned their petsan open-ended question.

\section{Pet Security}

Pet security was created by the researchers. The reliability of the scale was tested using Cronbach's Alpha based on standardized items and 0.847 was generated, hence, the measurement model demonstrated adequate reliability and convergent validity. However, before testing the reliability, a factor analysis was conducted and revealed only one factor. Mean of the scale was 15.64, variance 14.151 and standard deviation of 3.762. A 7-point Likert scale was used to ascertain whether respondents agree or disagree with the following three statements: $I$ feel secure whenever I am with my pet, I am not afraid whenever my pet is with me, and my pet makes me feel protected. The answer choices include very strongly agree, strongly agree, undecided, disagree, strongly disagree and very strongly disagree.

\section{Pet Attachment}

Ten questions were initially developed using emotional attachment scale by the researcher. However, a factorial analysis revealed two factors, even though the KMO and Bartlett's reliability test showed significance $(0.000)$ or $(0.884)$. To extract only one factor, four questions were removed. The six outstanding questions were then retested and item scale ranged from 0.613 to 0.826 . Scale reliability was 0.864 scale mean was 35.03 and SD was 6.03. Using a 7-point Likert scale, the respondents were asked to very strongly agree (7) or very strongly disagree (1) with the following statements: I feel closer to my pet than to many of my friends, I like my pet because hel she accepts me no matter what I do, I miss my pet when hel she is away from me, my pet recognizes my scent, my pet understands when I talk to him/ her and my pet gives me something to take care of. All questions were then considered valid and reliable.

\section{Pet Care}

To measure pet care, the respondents were asked to rate on a scale of 1 to 10 how much they care for their pets in the following areas: clean environment, fresh water, toys, pet diet, dental care, ample exercise, grooming and nail, and 
pet communication/training.

\section{Pet Loss}

Respondents were asked to use the 5-point Likert scale, where 5 is Definitely Yes and 1 is Definitely Not, to determine how they would react to the following statements: It would take me years to recover if my pet passed, I may need therapy to get over the loss of my pet and Losing my pet would devastate most of my activities. The scale was tested first using factor analysis and only one factor was extracted. Scale mean is 10.81 , SD (3.09). Cronbach's Alpha reliability is $(0.78)$ where item scale is $\geq 6.8$.

\section{Pet and Media}

To measure this variable, respondents were asked to rate on a scale of 0 to 10 how much the following forms of media has influenced their decision to own a pet-doctors, family and friends, social media, newspapers and magazines, radio and television and personal experience.

\section{Dependent Variables}

\section{Pet Preference for physical satisfaction}

Scale for pet preference for physical satisfaction was developed for this study. Cronbach's Alpha reliability reveals p (0.81) for pet physical preference, SD (3.75), and Mean (17.08). A 7-point likert scale (1 is very strongly disagree and 7 is very strongly agree) was used to ask respondents to agree or disagree with the following statement: Pet would give me more time than children, having pet is more economical than having children, pets are easier to control than children.

\section{Pet Preference for emotional satisfaction}

The researcher developed a scale for pet preference for emotional satisfaction. Again, Cronbach's Alpha reliability scale reveals (0.73) score, item mean of 3.92 and SD of 4.42. A 7-point Likert scale (1 is very strongly disagree and 7 is very strongly agree) was used to ask respondents to agree or disagree with the following statement: My pet gives me all the emotional support I would get from having children, with my pets, I don't feel the need to have children, and animals need more care than children in the United States.

\section{Results}

Data from the study showed that 133 (48.5\%) of the 274 pet owners owned only one pet while $71(26.2 \%)$ owned two pets. One $(0.8 \%)$ person said he owned pet 20 pets. The frequency of the number of pets is illustrated in Figure 1.

The most common pet owned by respondents was dog (39.1\%) 107, followed by cat $(36.5 \%) 100$. People who owned birds were only $4(1.5 \%)$. However, people who owned both cat and dog were 41 (15.0\%). The rest (8.2\%) had multiple combinations. Pet owners adopted (33.2\%) 91, bought (24.1\%) 66 or rescued their pets (22.6\%) 62. Some respondents found (9.5\%) 26 their pets while some received their through gifts (6.9\%) 19. Others (3.6\%) could not disclose where they got their pets from. Most of the respondents got their pets out of need for companionship and comfort (Table 2) while the mean length of pet ownership is 6.5 . 


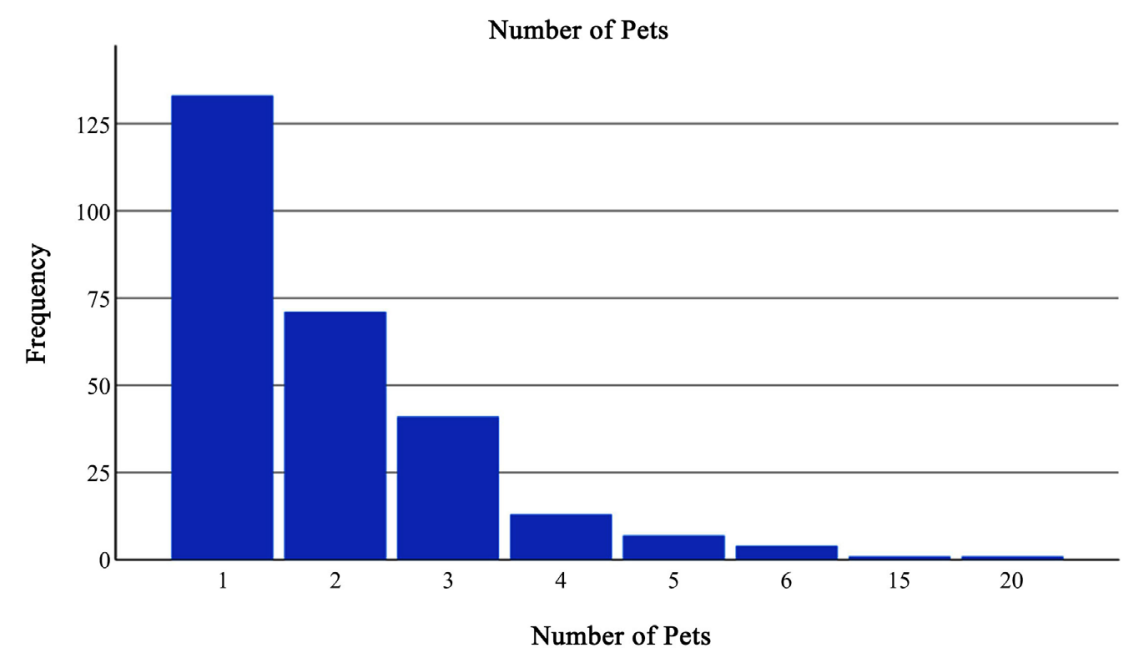

Figure 1. Number of pets.

Table 2. Reasons for pet purchase.

\begin{tabular}{ccc}
\hline Reasons & Mean & STD \\
\hline Medical & 0.70 & 1.8 \\
Comfort & 6.14 & 3.07 \\
Companionship & 8.86 & 1.95 \\
Security & 2.47 & 3.12 \\
To save life & 3.21 & 3.8 \\
Adorn home & 3.78 & 2.83 \\
\hline
\end{tabular}

\section{Results}

The first hypothesis predicted that the more single people acquire pets, the less likely they are to desire children. A regression analysis shows that there is no significance between number of pets owned and desire to have children for both physical, $F(0.27), R^{2}(0.001), p=0.600, \beta=-0.06, t(48.97)$ and emotional preferences, $F(2.5), R^{2}(0.006), p=0.114, \beta=-0.02, t(27.69)$. Tested with ANOVA, the resulted also reveals no significance. Desire for pets instead of children did not go up as number of pets went up.

The second hypothesis predicted that the more single people are attached to their pets, the less likely they are to want children. A simple linear regression depicts a significance between pet attachment and both physical $\left(F(21.176), R^{2}\right.$ (0.73), $\beta=0.2, p<0.001)$ ), and emotional ( $F(5.71, t(2.34), p(0.02), \beta=(0.4))$ preferences.

Hypothesis 3 envisaged that single people who experience high sense of security with their pets are less likely to desire children. Data analyzed shows no significant relationship between pet security and physical preference but an existence of relationship between pet security and emotional preference. Table 3 explains the data analyzed using ANOVA.

In hypothesis four, the author predicted that the longer people owned their 
pets, the more they are attached to their pets and not want children. There is no significant relationship between length of pet ownership and both physical and emotional variables based on the data in Table 4 .

The prediction of hypothesis five is that older people who have pets are less likely to desire children than younger people. Data shows that there is no difference between younger and older pet owners desires to have pets instead of children. An analysis of variance shows $p(0.966)$, men square, $0.003, \beta=$ -0.0003 and $t(29.63)=0.048$ for physical preference and $p(0.94), t(17.23)=$ 0.08 , mean square (0.013), $\beta=0.005$ for emotional preference.

Hypothesis six predicts that people who have fear of losing their pets would prefer pets than children. A simple regression analysis says there is no significance between pet loss and physical pet preference, $p$ (0.246), $t(1.16), \beta(0.071)$, mean of square (1.5), but a clear significance in pet loss and emotional preference, as shown in Table 5 .

Research question sought to find out the sources that have influenced pet owners' decisions to own a pet. Result showed that personal experience was the most influential source followed by family and friends. Doctors, newspapers/magazines and radio/T.V were the least influential (Table 6).

The second research question asked how much pet owners take care of their pets. Table 7 shows the details of which fresh water, diet, clean environment, toys, exercise. Grooming/nail, all had a mode of 10 except dental care (7) and pet communication/training (1).

Table 3. ANOVA for Hypothesis 3.

\begin{tabular}{cccccc}
\hline Mode & Sum of Squares & $d f$ & Mean Square & F & Sig \\
\hline Regression (emotional preference) & 26.1 & 1 & 26.01 & 12.6 & 0.000 \\
Residual & 556.7 & 273 & 2.8 & & \\
Total & 582.764 & 274 & & & \\
Regression (Physical preference) & 3.2 & 1 & 3.191 & 2.05 & 0.154 \\
Residual & 417.72 & 273 & & & \\
Total & 420.91 & 274 & & & \\
\hline
\end{tabular}

Table 4. Length of pet ownership.

\begin{tabular}{ccccc}
\hline Source & Dependent Variable & Sig & $\begin{array}{c}\text { Partial } \\
\text { Etasquared }\end{array}$ & $\begin{array}{c}\text { Noncent } \\
\text { parameters }\end{array}$ \\
\hline $\begin{array}{c}\text { Corrected } \\
\text { model }\end{array}$ & Physical Preference & 0.39 & 0.14 & 37.072 \\
& Emotional Preference & 0.18 & 0.16 & 43.1 \\
Intercept & Physical Preference & 0.000 & 0.86 & 486.7 \\
& Emotional Preference & 0.000 & 0.68 & 489.78 \\
How long & Physical Preference & 0.39 & 0.14 & 37.072 \\
& Emotional preference & 0.18 & 0.16 & 43.1 \\
\hline
\end{tabular}


Table 5. ANOVA regression for hypothesis 6.

\begin{tabular}{ccccccc}
\hline \multicolumn{7}{c}{ ANOVA $^{\mathrm{a}}$ Emotional Preference } \\
\hline \multicolumn{1}{c}{ Model } & Sum of Squares & df & Mean Square & F & Sig. \\
\hline \multirow{3}{*}{1} & Regression & 66.570 & 1 & 66.570 & 34.562 & $0.000^{\mathrm{b}}$ \\
& Residual & 516.194 & 268 & 1.926 & & \\
& Total & 582.764 & 269 & & & \\
\hline
\end{tabular}

Table 6. Source influence.

\begin{tabular}{ccc}
\hline Source & Mean & STD \\
\hline Personal experience & 9.31 & 8.13 \\
Family and friends & 5.29 & 8.93 \\
Social media & 2.02 & 2.83 \\
Radio/TV & 1.14 & 2.25 \\
Newspaper/magazines & 0.91 & 2.01 \\
Doctor & 0.84 & 1.98 \\
\hline
\end{tabular}

Table 7. Pet care.

\begin{tabular}{ccccc}
\hline Pet care & Mean & Mode & Median & STD \\
\hline Fresh water & 9.16 & 10 & 10 & 1.5 \\
Diet & 8.19 & 10 & 9 & 1.9 \\
Clean environment & 8.18 & 10 & 8 & 1.9 \\
Toys & 7.55 & 10 & 8 & 2.3 \\
Exercise & 2.28 & 10 & 7 & 2.3 \\
Grooming/nail & 7.08 & 10 & 8 & 2.4 \\
Dental care & 3.85 & 7 & 7 & 2.6 \\
Pet communication/training & 5.24 & 1 & 5 & 3.1 \\
\hline
\end{tabular}

\section{Discussion}

The findings of this study coincide with what other researchers have said about pet attachment. Pet owners feel attached to their pets more than their friends and their pets give them something to take care of. Not only that, the more people are attached to their pets, the more likely they are to feel safe and loved. Attachment to pets correlates with time, control and economy, meaning that people who are attached to their pets would most likely consider the fact that pets take more time, money and management than children. Also, intense attachment equals intense emotional submergence and belief that pets deserve care in the United States.

However, study shows no significance between pet attachment and pet preference, for even though respondents believed that pets are easier to take care of than children, they did not consider pets to be more important than children. 
Rather, they recognized the fact that both pets are children have different roles they play in people's lives and should be loved and preserved accordingly.

Nevertheless, the CDC report about women and men are choosing their careers over children and even those who want children would prefer not to have more than two, result of this study shows some if not many people having more than one pet, predominantly dogs and cats.

Studies have shown that people acquire pets because of companionship. This study agrees with other researchers as findings indicate that most pet owners got their pets out of need for companionship and comfort-same reason people have children. It is also common in America for pet owners to name their pets after loved ones who have passed or who they cherish-a common prove that most Americans consider pets as members of their families.

Although people feel safer and liberal having pets, security does not have any significance with physical preference to pet. Respondents agreed that preference to purchase a pet because of their cost and management does not have anything to do with feeling secured or protected with pets. On the other hand, result indicates that emotional support for pets and lack of need for children has a direct effect on emotional security. Pets can clearly provide the emotional attachment bond important in promoting a sense of security and well-being [41] [48]. This implies that people who feel very much safe with their pets would most likely have no need for children as their pets would dominate and satisfy their desire for children.

However, whether age is related to pet attachment is not supported by this study as findings show that there is no difference between older and younger owners' extent of attachment to their pets. Also, people who owned their pets for a very long time may or may not desire to have children- length of pet ownership did not show any significance to pet preference. This is contrary to the opinion that length of pet ownership increases pet attachment which in turn increases preferences for pet. This finding implies that how many years a person has owned a pet does not determine whether that person would decide to have pet or children in the future.

Contrary to previous findings that older people are more attached to their pets and feel closer to pets more than their friends or children [43], findings show that age has no significance; as a result, both young and old people could experience the same degree of attachment depending on several factors.

Pet loss has been found to be significant to emotional pet preference [26] confirming what previous researchers said about pet owners loving their pets so much that they even believe in their afterlife [23] [24] [49].

However, result indicates that pet owners would replace their pets and the possibility of needing therapy to recover over the loss of their pets is low and not significant [33]. Overall, the result of this study provides data for future discussants on population and psychological studies on per ownership and pet preference. Respondents stated that personal experience was their biggest motivation 
while considering whether to acquire pet or not. The respondents also stated that time, cost and management of pets were easier than children. Is this a call on the government to make to find ways to make child cost less expensive in the United States. The costs of day care and education are so overwhelmingly expensive that most people prefer to buy pets than have children.

This study calls on other researchers to investigate other factors asides pet ownership that could contribute to decreasing population rate in the United States. Social scientists should take it upon themselves to increase their interest in pet ownership literature.

\section{Conclusion}

The findings of this study call for a retrospection concerning the changes in the values of the citizens of the United States, to monitor population growth and to provide the facilities needed for the upkeep and care of children in the United States. The authors also recommend flexible childcare facilities in the country such as allowing new mothers maternity leave with pay and making working conditions less complex for mothers with newborn babies. Asides that, it is recommended that there should be legal restrictions on the amount of charges for daycare and nannies so that women find a balance between having children and working at the same time.

\section{Conflicts of Interest}

The authors declare no conflicts of interest regarding the publication of this paper.

\section{References}

[1] Information, I.I. (2018) Facts + Statistics: Pet Statistics.

[2] Lowry (2016) Why Are Millenials Having More Pet, Not Parenthood? Forbes.

[3] Cain, A.O. (2016) Pets as Family Members, in Pets and the Family. Routledge, Abingdon-on-Thames, 5-10. https://doi.org/10.4324/9781315784656-2

[4] Institute, P.I. (2018) Facts + Statistics: Pet Statistics.

[5] Edelson, J. and Lester, D. (1983) Personality and Pet Ownership: A Preliminary Study. Psychological Reports, 53, 990. https://doi.org/10.2466/pr0.1983.53.3.990

[6] Connell, C.M., et al. (2007) Are Pets a Source of Support or Added Burden for Married Couples Facing Dementia? Journal of Applied Gerontology, 26, 472-485. https://doi.org/10.1177/0733464807305180

[7] Walsh, F. (2009) Human-Animal Bonds II: The Role of Pets in Family Systems and Family Therapy. Family Process, 48, 481-499. https://doi.org/10.1111/j.1545-5300.2009.01297.x

[8] Beck, L. and Madresh, E.A. (2008) Romantic Partners and Four-Legged Friends: An Extension of Attachment Theory to Relationships with Pets. Anthrozoös, 21, 43-56. https://doi.org/10.2752/089279308X274056

[9] McNicholas, J., et al. (2005) Pet Ownership and Human Health: A Brief Review of Evidence and Issues. BMJ, 331, 1252-1254.

https://doi.org/10.1136/bmj.331.7527.1252 
[10] Hart, L.A., Hart, B.L. and Bergin, B.L. (1987) Socializing Effects of Service Dogs for People with Disabilities. Anthrozoös, 1, 41-44. https://doi.org/10.2752/089279388787058696

[11] Siegel, J.M. and Psychology, S. (1990) Stressful Life Events and Use of Physician Services among the Elderly: The Moderating Role of Pet Ownership. Journal of Personality and Social Psychology, 58, 1081-1086. https://doi.org/10.1037//0022-3514.58.6.1081

[12] Scheibeck, R., et al. (2011) Elderly People in Many Respects Benefit from Interaction with Dogs. European Journal of Medical Research, 16, 557-563. https://doi.org/10.1186/2047-783X-16-12-557

[13] Veevers, J.E. (2016) The Social Meanings of Pets: Alternative Roles for Companion Animals, in Pets and the Family. Routledge, Abingdon-on-Thames, 11-30. https://doi.org/10.4324/9781315784656-3

[14] Hart, L.A. (2003) Pets along a Continuum: Response to "What Is a Pet?" Anthrozoos, 16, 118-122. https://doi.org/10.2752/089279303786992288

[15] Saulny (2012) Hispanic Women Fall in US as Women Choose Smaller Families. New York Times.

[16] Daughtery (2019) CDC: Americans Not Having Enough Babies to Sustain Population, in the Hill.

[17] Miller (2018) Americans Are Having Fewer Babies: They Told Us Why. New York Times.

[18] Archer, J. and Winchester, G.J.B. (1994) Bereavement Following Death of a Pet. British Journal of Psychology, 85, 259-271. https://doi.org/10.1111/j.2044-8295.1994.tb02522.x

[19] Field, N.P., et al. (2009) Role of Attachment in Response to Pet Loss. Death Studies, 33, 334-355. https://doi.org/10.1080/07481180802705783

[20] Gerwolls, M.K. and Labott, S.M. (1994) Adjustment to the Death of a Companion Animal. Anthrozoös, 7, 172-187. https://doi.org/10.2752/089279394787001826

[21] Albert, A. and Bulcroft, K. (1988) Pets, Families, and the Life Course. Journal of Marriage and Family, 50, 543-552. https://doi.org/10.2307/352019

[22] Becker (2013) Over Half of U.S. Singles Own Pets, New Study Shows, in Healthy Pets.

[23] Carmack, B.J., et al. (2011) Pet Loss: The Interface of Continuing Bonds Research and Practice. Routledge/Taylor \& Francis Group, Abingdon-on-Thames, 273-284.

[24] Triebenbacher, S.L. (2006) The Companion Animal within the Family System: The Manner in Which Animals Enhance Life within the Home. In: Handbook on Animal-Assisted Therapy, Elsevier, Amsterdam, 357-374. https://doi.org/10.1016/B978-012369484-3/50018-9

[25] Testoni, I., et al. (2017) Pet Loss and Representations of Death, Attachment, Depression, and Euthanasia. Anthrozoös, 30, 135-148. https://doi.org/10.1080/08927936.2017.1270599

[26] Sharkin, B.S. and Knox, D.J. (2003) Pet Loss: Issues and Implications for the Psychologist. Professional Psychology: Research and Practice, 34, 414-421. https://doi.org/10.1037/0735-7028.34.4.414

[27] Sherman, D.G. (2017) Grief Counseling for Adult Pet Loss: A Primer for Mental Health Professionals. University of Alaska Fairbanks, Fairbanks.

[28] Cicchetti, D.J. (2010) Developmental Psychopathology. In: The Handbook of 
Life-Span Development, John Wiley \& Sons, Inc., Hoboken, 334-361. https://doi.org/10.1002/9780470880166.hlsd002014

[29] Morley, C. and Fook, J. (2005) The Importance of Pet Loss and Some Implications for Services. Mortality, 10, 127-143. https://doi.org/10.1080/13576270412331329849

[30] Zilcha-Mano, S., et al. (2011) Pet in the Therapy Room: An Attachment Perspective on Animal-Assisted Therapy. Attachment \& Human Development, 13, 541-561. https://doi.org/10.1080/14616734.2011.608987

[31] Gage, M.G. and Holcomb, R. (1991) Couples' Perception of Stressfulness of Death of the Family Pet. Family Relations, 40, 103-105. https://doi.org/10.2307/585666

[32] Carmack, B.J. (1985) The Effects on Family Members and Functioning after the Death of a Pet. Marriage and Family Reviews, 8, 149-161. https://doi.org/10.1300/J002v08n03_11

[33] Fiske, S.T. (1993) Social Cognition and Social Perception. Annual Review of Psychology, 44, 155-194. https://doi.org/10.1146/annurev.psych.44.1.155

[34] Fonagy, P. (2018) Attachment Theory and Psychoanalysis. Routledge, Abingdon-on-Thames. https://doi.org/10.4324/9780429472060

[35] Margolies, L. (1999) The Long Goodbye: Women, Companion Animals, and Maternal Loss. Clinical Social Work Journal, 27, 289-304. https://doi.org/10.1023/A:1022894320225

[36] Allen, K., Blascovich, J. and Mendes, W.B. (2002) Cardiovascular Reactivity and the Presence of Pets, Friends, and Spouses: The Truth about Cats and Dogs. Psychosomatic Medicine, 64, 727-739. https://doi.org/10.1097/00006842-200209000-00005

[37] Haggerty, J.M. and Mueller, M.K. (2017) Animal-Assisted Stress Reduction Programs in Higher Education. Innovative Higher Education, 42, 379-389. https://doi.org/10.1007/s10755-017-9392-0

[38] Gunter, B. (1999) Pets and People: The Psychology of Pet Ownership. Whurr Publishers.

[39] Quackenbush, J.E. (1982) Social Context of Pet Loss.

[40] Donohue, K.M. (2005) Pet Loss: Implications for Social Work Practice. Social Work, 50, 187-190. https://doi.org/10.1093/sw/50.2.187

[41] Katcher, A. and Friedmann, E. (1982) Potential Health Value of Pet Ownership (Companion Animals).

[42] Robin, M., et al. (1998) Pets and the Socialization of Children. In: Sussman, M.B., Ed., Pets and the Family, Taylor \& Francis Group, Abingdon-on-Thames, 105-120.

[43] Quackenbush, J.E. and Glickman, L. (1984) Helping People Adjust to the Death of a Pet. Health and Social Work, 9, 42-48. https://doi.org/10.1093/hsw/9.1.42

[44] Sussman, M.B. (2016) Pets and the Family. Routledge, Abingdon-on-Thames. https://doi.org/10.4324/9781315784656

[45] Finder, P. (2019) How Do Dogs Protect You and Mankind?

[46] Banks, T.J. (2017) Three Ways in Which Cats Are Protecting Humans. Petful.

[47] Animals H. F. (2019) The Importance of Pets. Global Animal Medicines Association.

[48] Ross, C.B. and Baron-Sorensen, J. (1998) Pet Loss and Human Emotion: Guiding Clients through Grief. Taylor \& Francis, Abingdon-on-Thames.

[49] Cusack, O. (2014) Pets and Mental Health. Routledge, Abingdon-on-Thames. https://doi.org/10.4324/9781315784618 
Variables

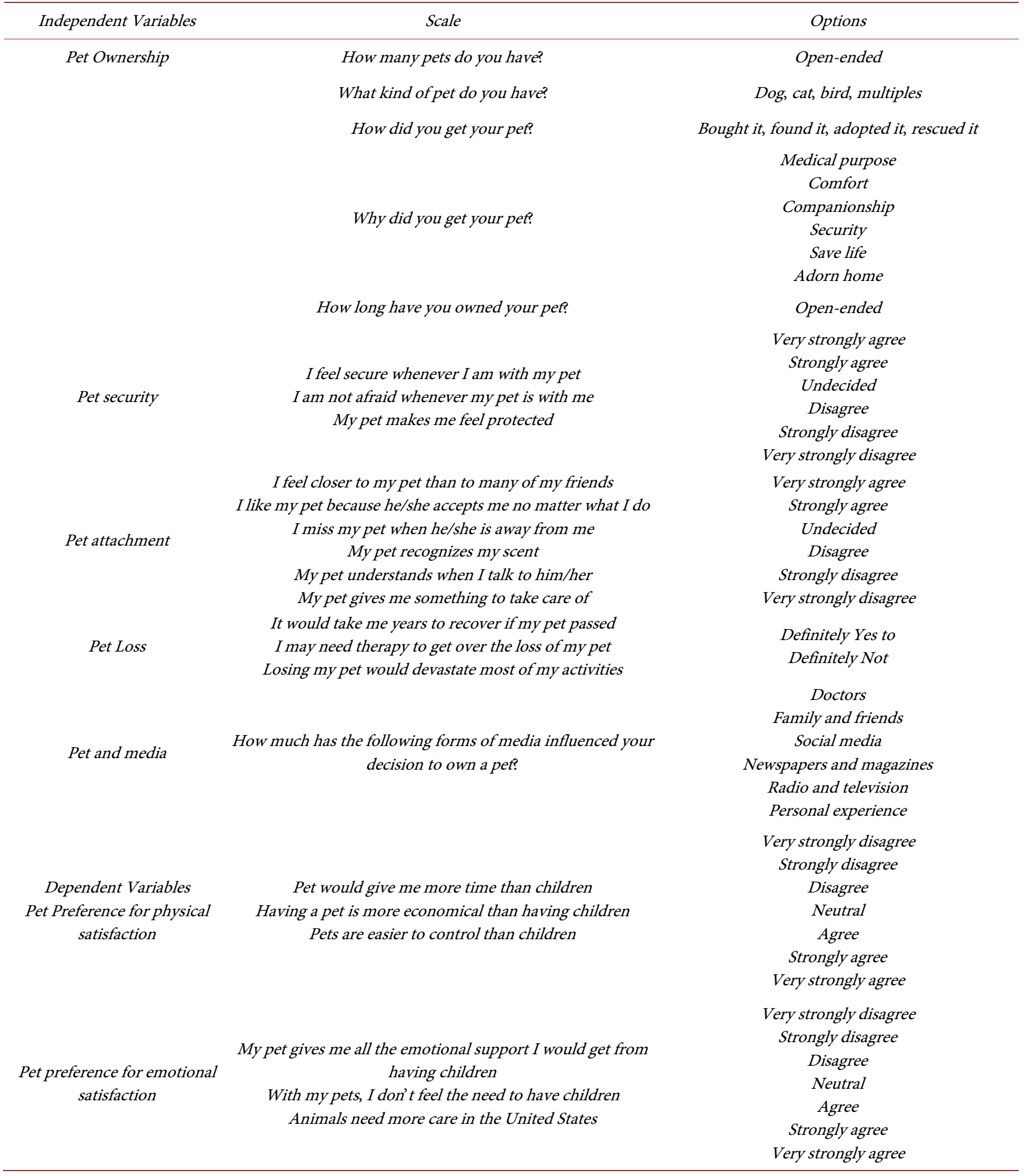

